\title{
Review Article \\ Status of the Reactive Extraction as a Method of Separation
}

\author{
Dipaloy Datta, ${ }^{1}$ Sushil Kumar, ${ }^{2}$ and Hasan Uslu ${ }^{3}$ \\ ${ }^{1}$ Chemical Engineering Department, Thapar University, Patiala 147004, India \\ ${ }^{2}$ Department of Chemical Engineering, Motilal Nehru National Institute of Technology (MNNIT), \\ Allahabad, Uttar Pradesh 211004, India \\ ${ }^{3}$ Chemical Engineering Department, Engineering and Architecture Faculty, Beykent University, Ayazağa, 34437 İstanbul, Turkey
}

Correspondence should be addressed to Hasan Uslu; hasanuslu@gmail.com

Received 7 August 2014; Accepted 20 September 2014

Academic Editor: Saeid Azizian

Copyright ( $\odot 2015$ Dipaloy Datta et al. This is an open access article distributed under the Creative Commons Attribution License, which permits unrestricted use, distribution, and reproduction in any medium, provided the original work is properly cited.

The prospective function of a novel energy efficient fermentation technology has been getting great attention in the past fifty years due to the quick raise in petroleum costs. Fermentation chemicals are still limited in the modern market in huge part because of trouble in recovery of carboxylic acids. Therefore, it is needed considerable development in the current recovery technology. Carboxylic acids have been used as the majority of fermentation chemicals. This paper presents a state-of-the-art review on the reactive extraction of carboxylic acids from fermentation broths. This paper principally focuses on reactive extraction that is found to be a capable option to the proper recovery methods.

\section{Introduction}

Liquid-liquid extraction (LLE) is a process in which a particular solute is removed from a liquid phase (feed phase) by another liquid phase (solvent or extract phase). Application of extraction in life science started in way back to about $3500 \mathrm{BC}$ to recover products from various natural resources. At a Sumerian text dated $2100 \mathrm{BC}$, production of perfumes, pharmaceutical oils, and waxes was documented. In medieval ages extraction was performed with ethanol and was applied in the field of hydrometallurgy by making use of mineral acids [1]. With the developments in thermodynamics, particularly the distribution law by Nernst in 1891 and design of an apparatus for extraction, significant improvements were accomplished in the late 19th century. However, it was not until the early 1930s when the first large-scale LLE process was in operation. Lazar Edeleanu (a Romanian Chemist: 18611941) removed aromatic and sulphur compounds from liquid kerosene by the LLE process using liquid sulphur dioxide as a solvent at temperature as low as -6 to $-12^{\circ} \mathrm{C}$. This yielded clean kerosene suitable to be used as a fuel for residential lighting. Nowadays, besides the extraction of almost all metals in mining industries and environmental applications, extractants are widely used in the extraction of organic and inorganic acids, organic chemistry intermediates, and pharmaceuticals for the purposes of separation, purification, or enrichment [2] of the product.

The main difference between reactive extraction and solvent extraction is the reaction between the extractant and the solute in the organic phase. Aliphatic amines and phosphoric solvents are proposed as effective extractants by earlier researchers [3]. While extractants play the major role in the reaction, diluents also have a significant effect on the level of extraction. Nonaromatic, water immiscible, and polar solvents with intermediate molecular weights and high boiling points are commonly preferred for the extraction to have high distribution and selectivity [4]. The solvents (diluents) control the physical properties (viscosity, density, surface tension, etc.) of the solvent phase and also affect the stability of the complex structure formed between the solute and the extractant.

The reactive extraction is found to be a promising method for the recovery of the carboxylic acids from a dilute fermentation broth [5-10]. This separation method has advantages such as the following:

(i) effective at high concentration of substrate in the extractive fermentation, 
(ii) the acid can be reextracted and the solvent can be reused,

(iii) better control of $\mathrm{pH}$ in the bioreactor,

(iv) better recovery of acid with higher product purity,

(v) reduction of downstream processing load and recovery cost,

(vi) reactants are relatively immiscible,

(vii) product(s) undergoes subsequent undesired reactions in reaction phase,

(viii) reaction products to be separated are immiscible with the reaction phase,

(ix) phase equilibrium can be positively influenced,

(x) heat transfer is to be improved during the reaction,

(xi) product-catalyst separation can be affected by a liquid-liquid separation.

Kertes and King [3] categorize the extractants as three major types:

(i) carbon bonded oxygen bearing extractants,

(ii) phosphorus bonded oxygen bearing extractants,

(iii) high molecular weight aliphatic amines.

The first two categories are nonreactive in nature and extract the acid molecules by solvation. The distinction between the first two categories is based on the strength of the solvation bonds and the specificity of solvation. The coordinate bonds between carbon bonded oxygen donor extractant and the acid are too weak for a specific solvation but it is significantly more for phosphorus bonded oxygen bearing extractants. The extractants in the second category make the solvation process more specific and the number of solvating molecules per extracted acid molecule can be accessible experimentally. The aliphatic amines in the third category can react with the carboxylic acid molecule and form acid-amine complexes by proton transfer or by ion pair formation. This causes a significant increase in the distribution coefficient of the carboxylic acid [11]. Among aliphatic amines, primary alkyl amines are observed to be excessively soluble in water at room temperature while secondary amines form a gel phase (third phase) at the interface which create difficulty in phase separation [3]. The extractability of tertiary amines is found to be more than that of the primary and secondary amines [5]. Aliphatic tertiary amines having more than six carbon atoms per chain are found to be effective extractants for the recovery of carboxylic acids [3].

Although a tertiary amine has good extractability, it must always be used with a diluent due to its viscous and corrosive nature. Further, the stability of the formed acidamine complexes in the reactive extraction is affected by the basicity of the amine which can be manipulated by using different types of diluents. Moreover, use of a diluent controls the physical properties such as density, viscosity, and surface tension of the organic phase [12].

Diluents can be broadly divided into two groups: (i) active diluents and (ii) inactive diluents. Generally, the active diluents are polar in nature due to the presence of functional groups. They are good solvating media for an ion-pair such as an acid-amine complex [13]. The category includes chlorinated hydrocarbon, ketone, alcohol, and halogenated aromatic solvents. Inactive diluents being nonpolar provide very low distribution of the acid and poor solvation of the polar complexes. Alkanes, benzene, alkyl substituted aromatics, and so forth fall in this category. These diluents limit the formation of the third phase at higher concentrations of acid in the organic phase and are useful in the stripping of acid. The equilibrium curve can be shifted towards the aqueous phase by increasing the concentration of the inert diluent in the mixture of diluents [14].

Reactive extraction represents a reaction between the acid (solute) and extractant molecule at the interface of aqueous and organic phase where transfers of acid molecules take place by the diffusion and solubilization mechanism. Reactive extraction strongly depends on various parameters such as aqueous phase composition, organic phase composition, types of complexes $(1: 1,2: 1$, etc.) formed, properties of the solvent (extractant and diluent), type of solvent, temperature, and $\mathrm{pH}$ [15]. The purpose should be achieving a high distribution coefficient with higher selectivity. This can be realized by utilizing an appropriate organic phase at optimum conditions.

There are two stages in extractive separation (Figure 1). The first is the extraction of the solute to produce a soluteextractant complex and a relatively solute free aqueous raffinate. The second step is necessary for stripping the solute from the organic complex to obtain amine free aqueous solute as a product and also for simultaneously regenerating the extractant recycled back to the extraction unit. In the second stage of reactive extraction, it is necessary to regenerate the organic phase. Tamada and King [16] have described two approaches for the regeneration of extractant-diluent system: (i) temperature swing regeneration and (ii) diluent swing regeneration. Yabannavar and Wang [17] have purified lactic acid from a loaded organic phase using sodium hydroxide $(\mathrm{NaOH})$ and hydrochloric acid $(\mathrm{HCl})$. Poole and King [18] have used an aqueous solution of low molecular weight amine for complete regeneration of organic phase.

Reactive extraction has many applications in chemical and pharmaceutical industries (intermediates, organic acids, vitamins...) or in hydrometallurgical and environmental science (heavy metals, inorganic acids...). The liquid ion exchangers are used to promote a certain reaction to accomplish very selective separations [19]. There are many liquid ion exchangers commercially available. They work basically with three different types of mechanisms: anion exchange, cation exchange, and solvation. It is practical to use ionexchangers in a diluent which is immiscible with water since they are highly viscous or solid materials. The diluent makes the organic phase easier to handle [1]

There are a significant number of studies on reactive extraction of organic acids in the literature. These studies investigate various aspects of reactive extraction of organic acids: chemical interactions between acids and extractants, reaction mechanisms, type of extractants and diluents, effect of temperature and $\mathrm{pH}$, effect of aqueous and organic phase 


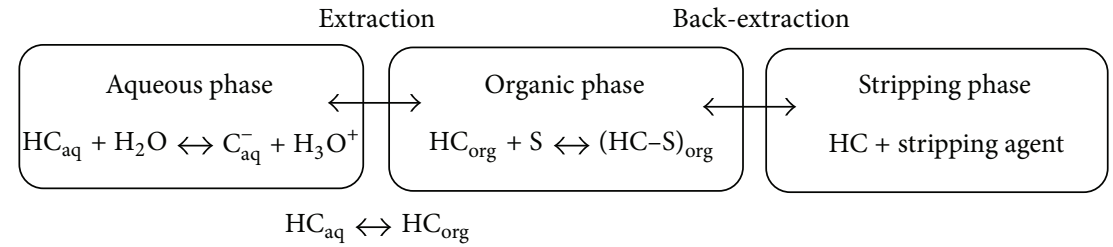

FIGURE 1: Schematic representation of the reactive extraction process (extraction and back-extraction).

compositions on extraction, effect of modifiers, extractive fermentation processes, kinetics of extraction, stripping the acid from the organic phase, and so forth.

\section{Equilibrium Studies on Reactive Extraction of Carboxylic Acids}

Several researchers $[3,8,9,13,16,21,26,31,56-59]$ have studied theoretical and experimental aspects of the recovery of carboxylic acids from their aqueous solutions by reactive extraction. In their work, the investigators have examined the effects of various parameters on the distribution of the acid (solute) between the aqueous and organic phase. Some of these parameters are concentration and composition of both phases, types of the extractants and diluents, $\mathrm{pH}$ of the aqueous phase, temperature of the system, and toxicity of the solvent phase to the microorganism [3, 13, 57, 60, 61]. In addition to these experimental studies, the possible reaction mechanisms are also described and determined using different equilibrium and kinetic models $[8,9,50$, 52]. Some experimental results have showed synergistic and antagonistic effects on the extraction of the carboxylic acids when there is more than one acid in the aqueous phase or more than one extractant in the organic phase $[21,62$, 63]. Some researchers have tried to recover the carboxylic acids from production medium by extractive fermentation and studied the process conditions affecting recovery during production [57, 60, 61, 64].

King and his group have performed the pioneering studies on the equilibrium of reactive extraction of carboxylic acids. Besides carboxylic acids, they have also studied the extraction of chlorinated hydrocarbons and aromatics [65], ethanol [66], ammonia [67], and low molecular weight aliphatic alcohols [3] from aqueous solutions. In one of their earlier work, Wardell and King [11] studied the extraction of acetic and formic acids from their aqueous solutions [11] using phosphoryl solvents (tributyl phosphate, dibutyl phosphonate, tributylphosphineoxide, and triphenylphosphineoxide) and tertiary amine extractants (tri- $n$-octylamine and tri-iso-octylamine) dissolving in different solvents. High distribution coefficients are achieved with phosphoryl compounds which act as a Lewis base (presence of the phosphoryl bond, $\mathrm{P}-\mathrm{O}$ ). The results indicated that, with the increase in the electronegativity, a decrease in the electron-donating ability and disappearance of Lewis basicity were observed. This study also showed the advantage of using long chain amines as extractants in the recovery of carboxylic acids. It was also observed that the extent of the extraction of acetic acid appeared to increase with an increase in the solubility parameter of the diluent besides the polarity.

At the later stage, Kertes and King [3], in 1986, published a research article in which the authors discussed the improvements in fermentation technology and its need of commercialization. They have reviewed 11 carboxylic acids (propionic, pyruvic, lactic, succinic, fumaric, maleic, itaconic, tartaric, citric, and isocitric) which are obtained by aerobic fermentation of glucose via the glycolytic pathway and glyoxylate bypass. The investigators pointed out that it is the undissociated part of a monocarboxylic acid which can only be extracted into carbon-bonded and phosphorus-bonded solvent. This revealed that the initial $\mathrm{pH}$ of the aqueous solution and the dissociation constant $\left(\mathrm{p} K_{a}\right)$ of the acid are two very important and influential parameters in the extraction of particular acid. Mass action law and Nernst distribution law are used in order to evaluate the data. The authors have considered the dimerization of acids in the organic phase and proposed a relation between dimerization constant and partition coefficient. The emphasis is given for the use of aliphatic tertiary amines compared to primary and secondary amines. In particular, monocarboxylic acids under comparable conditions are noted to be more easily extracted with an appropriate organic phase than di- or tri-carboxylic acids [3].

King and his coworkers $[13,16,56]$ continued their studies on reactive extraction of carboxylic acids. In their first study [13], they have carried out the extraction equilibrium experiments of carboxylic acids (acetic, lactic, succinic, malonic, fumaric, and maleic) with different $\mathrm{p} K_{a}$ values. They have studied the effect of $\mathrm{p} K_{a}$ of the corresponding acid on the extent of extraction. It is found that the acid with higher $\mathrm{p} K_{a}$ value is extracted in more amounts. Furthermore, they have also searched for the effect of functional groups present in acid other than the primary carboxyl group on extraction. The reactive extraction is examined using Alamine 336 dissolved in various diluents (active diluents: 1-octanol, DCM, chloroform, MIBK, nitrobenzene; inert diluent: heptane). These diluents are selected with different chemical characteristics such as electron donating, electron accepting, polar and nonpolar in order to observe the effect of diluent-complex interactions on the equilibrium conditions and the possible formation of acid-amine complexes $(1: 1$, $2: 1)$. They have indicated that solubility of the acid-amine complex in the solvent phase is decreased in the following order: alcohol $\geq$ nitrobenzene $\geq$ proton donating halogenated hydrocarbon $>$ ketone $>$ halogenated aromatic $>$ benzene $>$ alkyl aromatic $>$ aromatic hydrocarbon. 
In their second study, Tamada and King [56] have investigated the chemical interactions between the components by using the results of mass action law analysis and the spectroscopic studies. Organic phase is analyzed by infrared spectroscopy to examine the stoichiometry of the acid-amine complex. They emphasize that there is an ion pair formation between the amine and first acid molecule and there is a hydrogen bond formation between the carboxyl of the second acid molecule and the carboxylate of the first in the formation of $2: 1$ complex of acid-amine.

In the last part of the study [16], this group has carried out the coextraction of water with the acids by Alamine 336 dissolved in various diluents and found that amine had no effect on the coextraction of water. Water coextraction was decreased in the order of 1-octanol $>$ MIBK $>$ nitrobenzene $>$ methylene chloride $>$ chloroform $>$ heptane during the extraction of succinic acid. Coextraction of water for different acids is also compared and it is revealed that monocarboxylic acids carry less water than dicarboxylic acids. In this study, the effect of the temperature on the reactive extraction of carboxylic acids by Alamine 336 is performed. It is observed that the distribution coefficient decreased with the increase in the temperature of the system as with the formation of the complex, the system became more ordered and entropy decreased. Consequently, the amount of acid extracted decreased with the increase in temperature. Finally, King and his coworkers regenerated the extractant through back-extraction by two approaches: swing temperature and swing diluent methods.

The quaternary amines are first studied by Yang et al. [68]. They have investigated Alamine 336 and Aliquat 336, quaternary amine produced by the methylation of Alamine 336 and composed of a large organic cation with a chloride ion, dissolved in kerosene or 2-octanol to extract lactic, acetic, and propionic and butyric acids. It has been reported that while Alamine 336 can extract only the undissociated acid, Aliquat 336 can extract both dissociated and undissociated acids and always gives higher distribution coefficients than Alamine 336 at all $\mathrm{pH}$ values. It is also reported in this study that the extraction power of Alamine 336 is increased by the polar diluent, 2-octanol. On the other hand a diluent effect could not be detected on the extraction power of Aliquat 336 .

Procházka et al. [69] have studied trialkylamine, a mixture of straight chain tertiary amine with 7-9 carbon atoms, dissolved in the mixture of 1-octanol and n-heptane to extract lactic, malic and citric acids. It is reported that all systems used in this study are sensitive to temperature and solvent composition. In another study, Juang et al. [21, 70] used a tertiary amine based extractant, tri- $n$-octylamine (TOA) dissolved in xylene to extract succinic and tartaric acids $[21,70]$. They obtained thermodynamic data on extraction and compared extraction equilibria of succinic and tartaric acids with TOA dissolved in xylene. They have reported that the equilibrium distribution coefficient of the acids extracted with TOA increases with initial concentration of amine in the organic phase and of the acid in the aqueous phase. TOA has also been investigated by Poposka et al. [71] as an extractant dissolved in an iso decanol/n heptane mixture for extraction equilibria of citric acid. The data were obtained as a function of acid, amine and isodecanol concentrations at $298 \mathrm{~K}$ and an appropriate mathematical model was proposed.

Most of the studies on reactive extraction in the literature are focused on a single acid in the aqueous phase. However, Juang et al. [70] have reported that extraction characteristics are affected by the presence of more than one acid in the aqueous phase. Separation mechanisms of lactic and citric acids in the aqueous phase with TOA dissolved in xylene have been investigated via the supported liquid membrane technique. They have reported large synergistic effects compared to single acid systems for low initial concentration ratio of citric to lactic acid $(\alpha)$ and an antagonistic effect at $\alpha=2$. The presence of the second acid has a positive effect on the transport of citric acid but a negative effect on that of the lactic acid. Transport rate of the acids also increases with TOA concentration and temperature. New synergistic extraction system for organic acids was developed by Matsumoto et al. [72]. The extraction equilibria were investigated for acetic, glycolic, propionic, lactic, succinic, fumaric, malic, and itaconic acids by tri- $n$-octylamine (TOA) and/or tri-n-butylphosphate (TBP) dissolved in hexane. It is reported that when a mixture of extractants are used a synergy is developed and a more effective extraction of all organic acids is achieved.

The above studies clearly show that the reaction between the extracted acid and the extractant present in the organic phase is dependent on the corresponding acid and the contents of the organic phase. To explore the possibilities of reactive extraction and its application and commercialization, further studies are carried out with different carboxylic acids using various extractants dissolved in different categories of diluents. A brief review of these extraction studies is summarized in a tabular form and shown in Table 1 to have a clear understanding of the various reactive systems used.

2.1. Equilibrium Models. The theories of equilibria of reactive extraction are explained in this section. The model describes the physical and chemical phenomena occurring in the extraction process in the mathematical forms. They also explain interaction mechanism between the components of aqueous (acid and water) and organic (extractant and/or diluent) phases. In these model equations, assumption is made that all the reactions are in thermodynamic equilibrium occurring at the interface of aqueous and organic phases.

2.1.1. Mass Action Law Model. Equilibrium data are interpreted by Mass Action Law, which was proposed by Guldberg and Waage in 1864. Kertes and King in 1986 [3] applied Mass Action Law for reactive extraction of carboxylic acids. In the Mass Action Law model, activities of the aqueous and organic phase species are assumed to be proportional to the respective concentration of the species and the equilibrium constant takes care of the constant of proportionality or the nonidealities associated with the reactive system. Therefore, the apparent equilibrium constant (written in terms of species concentration) is used for the development of mathematical model of the reaction equilibrium. This model can be subcategorized in two types: (i) physical extraction where only 


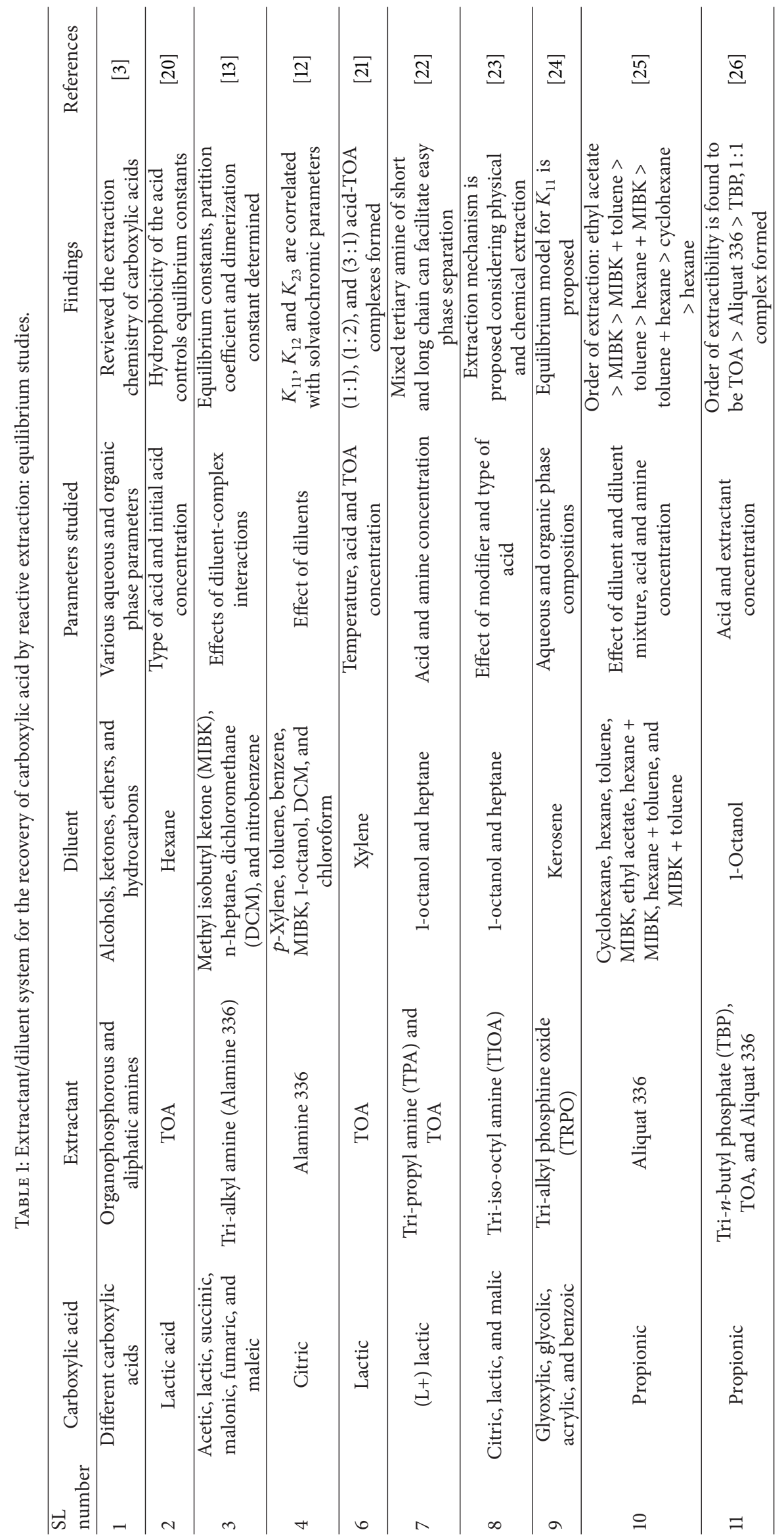




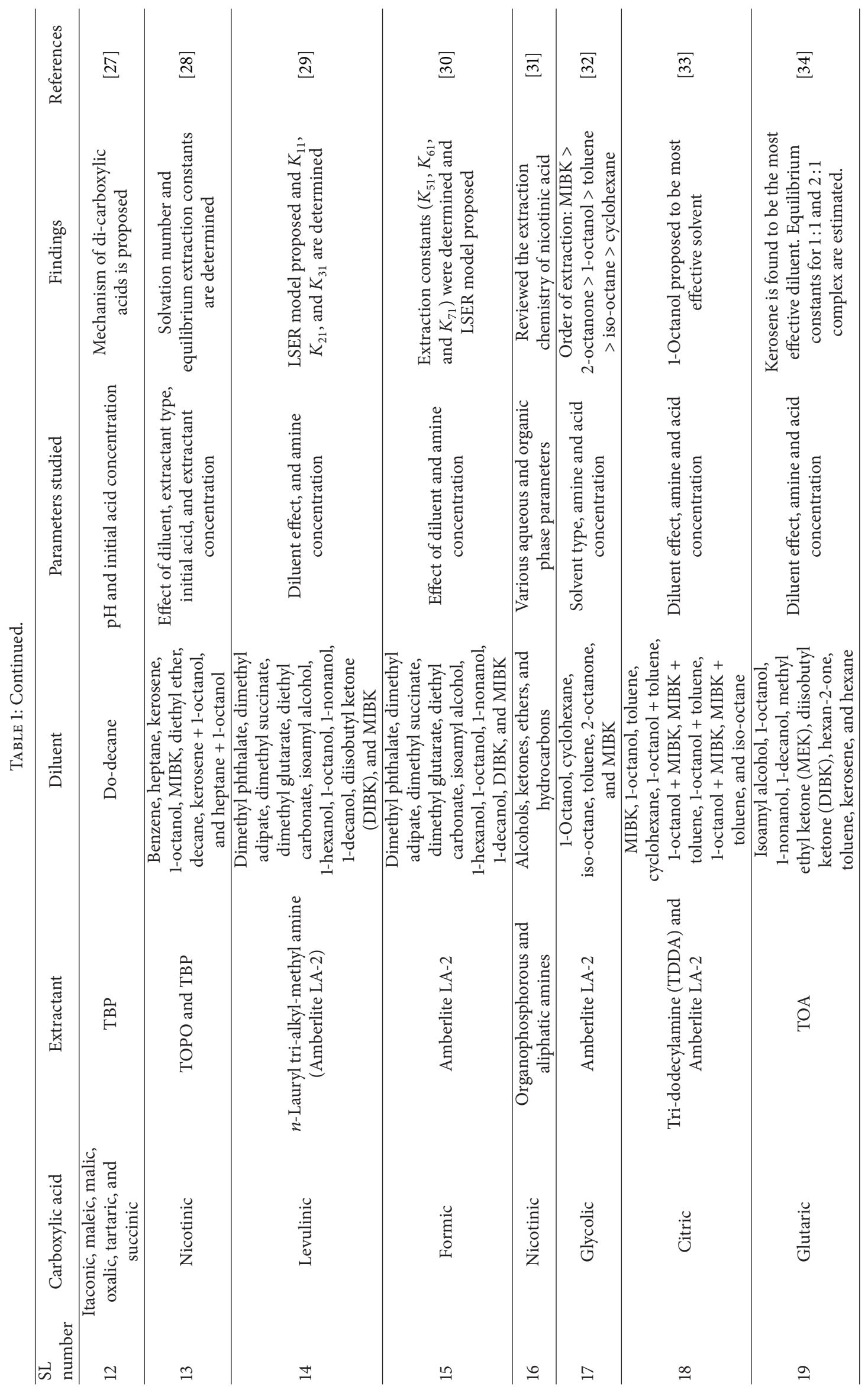




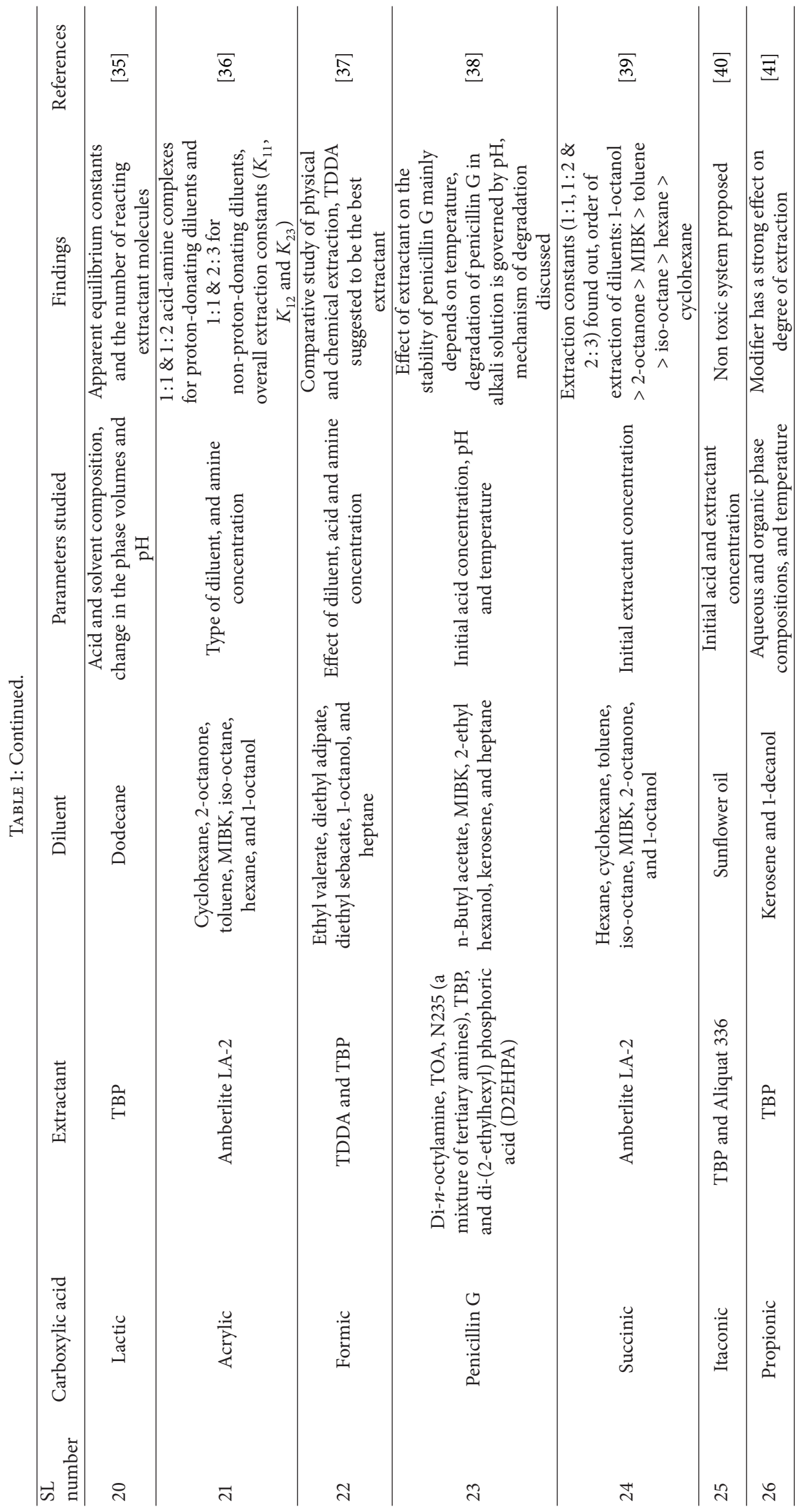




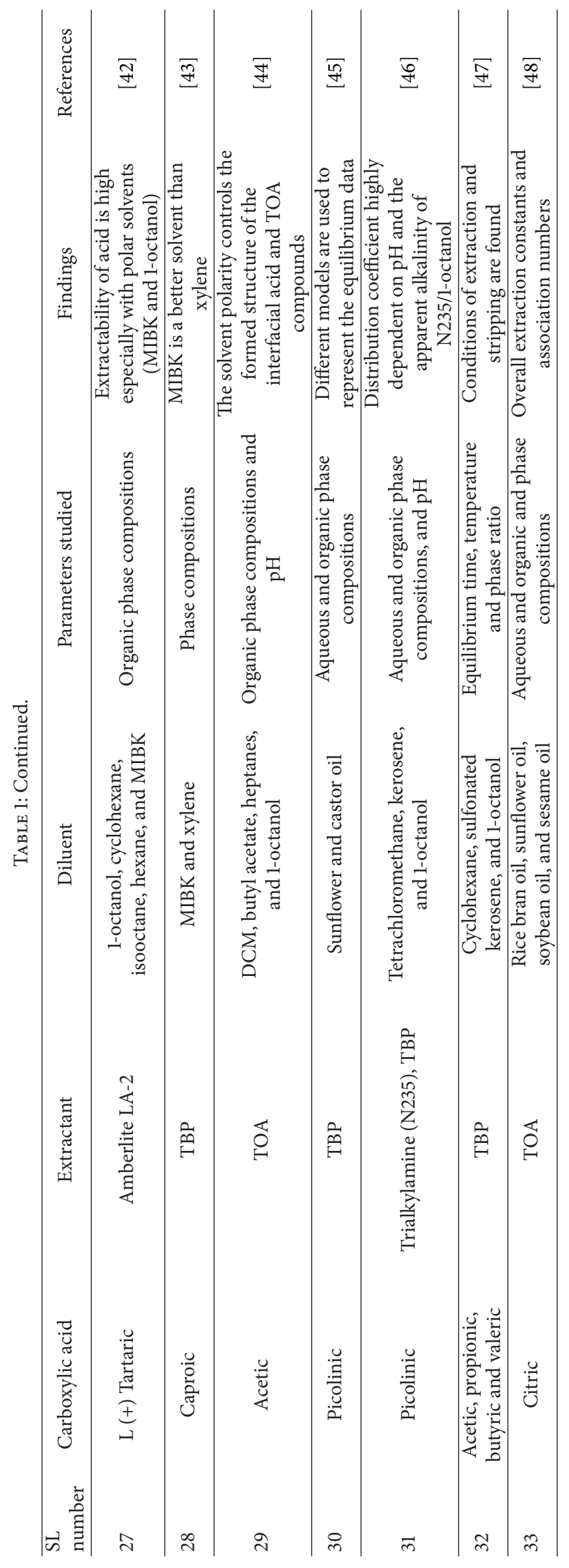


diluent (pure form) is used for extraction and (ii) chemical extraction where both extractant (phosphoric and aminic) and diluent take part in the extraction process.

(1) Physical Extraction. The process of physical equilibria with pure diluent takes place in three parts: (i) partial dissociation of the acid molecule in aqueous phase, (ii) distribution of the undissociated acid molecule between aqueous and organic phases, and (iii) dimerization of undissociated acid molecule in the organic phase.

(i) Carboxylic acid can exist in undissociated (HC) and dissociated $\left(\mathrm{C}^{-}\right)$forms in the aqueous solution of water. The dissociation of the acid in the aqueous solution depends upon the strength of the acid $\left(\mathrm{p} K_{a}\right)$ and is described by

$$
\mathrm{HC} \longleftrightarrow \mathrm{H}^{+}+\mathrm{C}^{-}
$$

The dissociation constant $\left(K_{a}\right)$ is calculated using

$$
K_{a}=\frac{\left[\mathrm{H}^{+}\right]\left[\mathrm{C}^{-}\right]}{[\mathrm{HC}]} .
$$

The total acid concentration in the aqueous phase $\left(C_{\mathrm{HC}}\right)$ and undissociated acid [HC] concentration can be expressed as (3) and (4), respectively:

$$
\begin{gathered}
C_{\mathrm{HC}}=[\mathrm{HC}]+\left[\mathrm{C}^{-}\right] \\
{[\mathrm{HC}]=\frac{C_{\mathrm{HC}}}{\left(1+\left(K_{a} /\left[\mathrm{H}^{+}\right]\right)\right)} .}
\end{gathered}
$$

(ii) The distribution of the undissociated acid molecule between aqueous and organic phases is represented by (5) and the corresponding partition coefficient is given by (6):

$$
\begin{gathered}
\mathrm{HC} \longleftrightarrow \overline{\mathrm{HC}} \\
P=\frac{\overline{[\mathrm{HC}]}}{[\mathrm{HC}]} .
\end{gathered}
$$

(iii) The undissociated extracted acid molecules can dimerize in the organic phase due to the strong donoracceptor interaction. This is due to the solute-solute interaction through hydrogen bond which is stronger than the solute-solvent interaction. The dimerization of the undissociated extracted acid in the organic phase $(\overline{\mathrm{HC}})$ is represented by

$$
2 \overline{\mathrm{HC}} \longleftrightarrow(\overline{\mathrm{HC}})_{2}
$$

The dimerization constant $(D)$ is expressed by

$$
D=\frac{\overline{(\mathrm{HC})}_{2}}{\overline{(\mathrm{HC})}^{2}} \text {. }
$$

The extraction efficiency (with pure diluent) of acid is calculated by the physical distribution coefficient, $K_{D}^{\text {diluent }}$ :

$$
K_{D}^{\text {diluent }}=\frac{\bar{C}_{\mathrm{HC}}^{\text {diluent }}}{C_{\mathrm{HC}}^{\text {diluent }}},
$$

where $\bar{C}_{\mathrm{HC}}^{\text {diluent }}$ is the total (undissociated and dimer forms) concentration of acid in the organic phase and $C_{\mathrm{HC}}^{\text {diluent }}$ is the total (dissociated and undissociated) concentration in aqueous phase at equilibrium with pure diluent.

For a dilute concentration of acid (as used in this study), $K_{D}^{\text {diluent }}$ in terms of dimerization constant $(D)$ and partition coefficient $(P)$ can be represented as [3]

$$
K_{D}^{\text {diluent }}=P+2 D P^{2}[\mathrm{HC}] .
$$

To estimate the values of physical extraction parameters $(P$ and $D$ ), the plots of $K_{D}^{\text {diluent }}$ versus [HC] can be fitted linearly and value of $P$ from the intercept and $D$ from the slope can be obtained.

(2) Chemical Extraction. The interaction of acid molecule with the extractant molecule in the chemical extraction can occur in two ways: (i) through hydrogen bonding of undissociated acid molecule, (11) and (ii) by ion pair formation, (12) [73]:

$$
\begin{gathered}
\mathrm{HC}+\overline{\mathrm{S}} \longleftrightarrow \overline{(\mathrm{HC})(\mathrm{S})} \\
\mathrm{H}^{+}+\mathrm{C}^{-}+\overline{\mathrm{S}} \longleftrightarrow \overline{\mathrm{H}^{+} \mathrm{C}^{-} \mathrm{S}}
\end{gathered}
$$

The extraction mechanism described in (11) and (12) depends on the $\mathrm{pH}$ of aqueous solution, $\mathrm{p} K_{a}$ of acid, the acid and extractant concentrations, and the basicity of the extractant with respect to the acid $\left(\mathrm{p} K_{B}\right)$. The extraction of carboxylic acid by phosphorous based extractants (TBP, TOPO, etc.) can be described by (11) and that for amine based extractants (TOA, Aliquat 336, etc.) by both mechanisms (11) and (12).

An equilibrium extraction process is described as a set of reactions (see (13)) between $m$ molecules of acid (HC) and $n$ molecules of extractant $(\mathrm{S})$ to form various $(m: n)$ complexes with corresponding apparent equilibrium constant $\left(K_{E}\right)$ as given by (14):

$$
\begin{gathered}
m \mathrm{HC}+n \overline{\mathrm{S}} \longleftrightarrow \overline{(\mathrm{HC})_{m}(S)_{n}} \\
K_{E}=\frac{\left[\overline{(\mathrm{HC})_{m}(\mathrm{~S})_{n}}\right]}{[\mathrm{HC}]^{m}[\overline{\mathrm{S}}]^{n}} .
\end{gathered}
$$

The distribution coefficient $\left(K_{D}\right)$ can be written as

$$
K_{D}=\frac{\bar{C}_{\mathrm{HC}}}{C_{\mathrm{HC}}}=m \frac{\left[\overline{(\mathrm{HC})_{m}(S)_{n}}\right]}{C_{\mathrm{HC}}} .
$$

Substituting the values of $[\mathrm{HC}]$ and $\left[\overline{(\mathrm{HC})_{m}(S)_{n}}\right]$ from $(4)$ and (15), respectively, in (14) results in

$$
K_{E}=\frac{K_{D}\left(1+K_{a} /\left[\mathrm{H}^{+}\right]\right)^{m}}{m C_{\mathrm{HC}}^{m-1}[\overline{\mathrm{S}}]^{n}} .
$$

The equilibrium free extractant concentration $([\overline{\mathrm{S}}])$ in the organic phase is represented as

$$
\begin{gathered}
{[\mathrm{S}]=[\overline{\mathrm{S}}]_{\mathrm{in}}-n\left[\overline{(\mathrm{HC})_{m}(\mathrm{~S})_{n}}\right]} \\
{[\overline{\mathrm{S}}]=[\overline{\mathrm{S}}]_{\text {in }}-\frac{K_{D^{n} C_{\mathrm{HC}}}}{m} .}
\end{gathered}
$$


Now, putting the value of $[\overline{\mathrm{S}}]$ from (18) in (16), (19) is derived:

$$
K_{D}=m K_{E}\left([\overline{\mathrm{S}}]_{\mathrm{in}}-K_{D} n \frac{C_{\mathrm{HC}}}{m}\right)^{n} \frac{C_{\mathrm{HC}}^{m-1}}{\left(1+K_{a} /\left[\mathrm{H}^{+}\right]\right)^{m}} .
$$

The values of equilibrium extraction constant $\left(K_{E}\right)$ and the stoichiometry $(m, n)$ of the reactive extraction are determined by minimizing the error between the experimental and predicted values of $K_{D}$.

The equilibrium model for the simultaneous formation of various types of acid-extractant complexes $(1: 1,2: 1,3: 1,1: 2$, etc.) can be represented by a system of equations (see (20) to (23)) depending upon the type of the acid, extractant, and diluent and their concentrations used in the experiment.

$$
\begin{gathered}
\mathrm{HC}+\overline{\mathrm{S}} \longleftrightarrow \overline{(\mathrm{HC})(\mathrm{S})} \\
\mathrm{HC}+\overline{(\mathrm{HC})(\mathrm{S})} \longleftrightarrow \overline{(\mathrm{HC})_{2}(\mathrm{~S})} \\
\mathrm{HC}+\overline{(\mathrm{HC})_{2}(\mathrm{~S})} \longleftrightarrow \overline{(\mathrm{HC})_{3}(\mathrm{~S})} \\
\overline{(\mathrm{HC})(\mathrm{S})}+\overline{\mathrm{S}} \longleftrightarrow \overline{(\mathrm{HC})(\mathrm{S})_{2}}
\end{gathered}
$$

The corresponding extraction constants $\left(K_{11}, K_{21}, K_{31}\right.$ and $K_{12}$ ) are calculated using (24) to (27):

$$
\begin{gathered}
K_{11}=\frac{\overline{\mathrm{C}}_{11}\left(1+K_{a} /\left[\mathrm{H}^{+}\right]\right)}{C_{\mathrm{HC}}[\overline{\mathrm{S}}]} \\
K_{21}=\frac{\overline{\mathrm{C}}_{21}\left(1+K_{a} /\left[\mathrm{H}^{+}\right]\right)}{C_{\mathrm{HC}} \overline{\mathrm{C}}_{11}} \\
K_{31}=\frac{\overline{\mathrm{C}}_{31}\left(1+K_{a} /\left[\mathrm{H}^{+}\right]\right)}{C_{\mathrm{HC}} \overline{\mathrm{C}}_{21}} \\
K_{12}=\frac{\overline{\mathrm{C}}_{12}}{\overline{\mathrm{C}}_{11}[\overline{\mathrm{S}}]} .
\end{gathered}
$$

$\overline{\mathrm{C}}_{11}, \overline{\mathrm{C}}_{21}, \overline{\mathrm{C}}_{31}$, and $\overline{\mathrm{C}}_{12}$ are the concentrations of $1: 1,2: 1,3: 1$, and $1: 2$ complexes, respectively, in the organic phase. $\bar{C}_{\mathrm{HC}}$ and $[\overline{\mathrm{S}}]$ are given by (28) and (29), respectively:

$$
\begin{aligned}
\overline{\mathrm{C}}_{\mathrm{HC}}= & \overline{\mathrm{C}}_{11}+2 \overline{\mathrm{C}}_{21}+3 \overline{\mathrm{C}}_{31}+\overline{\mathrm{C}}_{12} \\
= & \frac{K_{11}[\overline{\mathrm{S}}] C_{\mathrm{HC}}}{\left[1+K_{a} /\left[\mathrm{H}^{+}\right]\right]}+\frac{2 K_{11} K_{21}[\overline{\mathrm{S}}] C_{\mathrm{HC}}^{2}}{\left[1+K_{a} /\left[\mathrm{H}^{+}\right]\right]^{2}} \\
& +\frac{3 K_{11} K_{21} K_{31}[\overline{\mathrm{S}}] C_{\mathrm{HC}}^{3}}{\left[1+K_{a} /\left[\mathrm{H}^{+}\right]\right]^{3}}+\frac{K_{11} K_{12}[\overline{\mathrm{S}}]^{2} C_{\mathrm{HC}}}{\left[1+K_{a} /\left[\mathrm{H}^{+}\right]\right]}
\end{aligned}
$$

$$
\begin{aligned}
& {[\overline{\mathrm{S}}]=[\overline{\mathrm{S}}]_{\text {in }}-}\left(\overline{\mathrm{C}}_{11}+\overline{\mathrm{C}}_{21}+\overline{\mathrm{C}}_{31}+2 \overline{\mathrm{C}}_{12}\right) \\
&=[\overline{\mathrm{S}}]_{\mathrm{in}}-\left(\frac{K_{11}[\overline{\mathrm{S}}] \mathrm{C}_{\mathrm{HC}}}{\left[1+K_{a} /\left[\mathrm{H}^{+}\right]\right]}+\frac{K_{11} K_{21}[\overline{\mathrm{S}}] \mathrm{C}_{\mathrm{HC}}^{2}}{\left[1+K_{a} /\left[\mathrm{H}^{+}\right]\right]^{2}}\right. \\
&+\frac{K_{11} K_{21} K_{31}[\overline{\mathrm{S}}] \mathrm{C}_{\mathrm{HC}}^{3}}{\left[1+K_{a} /\left[\mathrm{H}^{+}\right]\right]^{3}} \\
&\left.+\frac{2 K_{11} K_{12}[\overline{\mathrm{S}}]^{2} C_{\mathrm{HC}}}{\left[1+K_{a} /\left[\mathrm{H}^{+}\right]\right]}\right) .
\end{aligned}
$$

Using experimental results and by applying the mass action law, the values of the individual equilibrium constants $\left(K_{11}\right.$, $K_{21}, K_{31}$ and $\left.K_{12}\right)$ and the concentration of complexes $\left(\overline{\mathrm{C}}_{11}\right.$, $\overline{\mathrm{C}}_{21}, \overline{\mathrm{C}}_{31}$, and $\overline{\mathrm{C}}_{12}$ ) can be estimated. An objective function can be defined to determine individual equilibrium constants based on experimental values of $\bar{C}_{\mathrm{HC}}$.

Now, a model based on the loading ratio $(Z)$ for formation of various types of complexes $(1: 1,2: 1$, etc.) between acid and extractant can also be described. The extent to which the organic phase (extractant and diluent) may be loaded with acid is expressed by the loading ratio. It is a ratio of acid concentration in the organic phase at equilibrium to the initial extractant concentration in the organic phase $\left([\overline{\mathrm{S}}]_{\mathrm{in}}\right)$ :

$$
Z=\frac{\bar{C}_{\mathrm{HC}}}{[\overline{\mathrm{S}}]_{\text {in }}}
$$

The value of $Z$ depends on the extractability of the acid (strength of the acid-base interaction) and its aqueous concentration and the stoichiometry of the overall extraction equilibrium. It is found that when the organic phase is not highly concentrated by acid, that is, at very low loading ratios $(Z<0.5), 1: 1$ acid-extractant complex is formed. A plot of $Z /(1-Z)$ versus $[\mathrm{HC}]$ yields a straight line passing through origin with a slope of complexation constant $\left(K_{11}\right)$ as given by (31):

$$
\frac{Z}{1-Z}=K_{11}[\mathrm{HC}]
$$

If the carboxylic acid concentration is high enough (at least $Z>0.5$ ), this relation can be expressed as shown by

$$
\frac{Z}{m-Z}=K_{m 1}[\mathrm{HC}]^{m} \text {. }
$$

To account for the extraction only by extractant, a term is defined for the distribution of acid by chemical extraction $\left(K_{D}^{\text {chem }}\right)$ as

$$
K_{D}^{\text {chem }}=\frac{\bar{C}_{\mathrm{HC}}-\nu \bar{C}_{\mathrm{HC}}^{\text {diluent }}}{C_{\mathrm{HC}}},
$$

where $v$ is the volume fraction of diluent in the organic phase.

Therefore, the overall distribution coefficient $\left(K_{D}^{\text {total }}\right)$ by physical and chemical extraction is obtained by adding (9) and (33).

$$
K_{D}^{\text {total }}=\nu K_{D}^{\text {diluent }}+K_{D}^{\text {chem }}
$$


In general the diluent alone also solvates some amount of solute (acid) from aqueous solution by physical extraction which is described in the previous section. Therefore, in such a case, expression for $\left[\overline{(\mathrm{HC})_{m}(\mathrm{~S})_{n}}\right]$ is represented as

$$
\left[\overline{(\mathrm{HC})_{m}(\mathrm{~S})_{n}}\right]=\bar{C}_{\mathrm{HC}}-\nu \bar{C}_{\mathrm{HC}}^{\text {diluent }}
$$

Therefore, (35) could be obtained by including the term for physical extraction and rewriting (34) as

$$
K_{m n}[\mathrm{HC}]^{m}=\frac{\bar{C}_{\mathrm{HC}}-\nu \bar{C}_{\mathrm{HC}}^{\text {diluent }}}{\left[[\overline{\mathrm{S}}]_{\mathrm{in}}-n\left(\bar{C}_{\mathrm{HC}}-\nu \bar{C}_{\mathrm{HC}}^{\text {diluent }}\right)\right]^{n}} .
$$

2.1.2. Linear Solvation Energy Relation (LSER). A linear solvation energy relationship (LSER) approach has been introduced by Kamlet et al. [74] in 1983 and then improved by Abraham [75]. It characterizes solvation effects in terms of nonspecific and $\mathrm{H}$-bonding interactions. Thus, a solvation property of interest $(X Y Z)$ for an organic solute is modeled by a linear solvation energy relationship of the form [76]

$$
X Y Z=X Y Z^{0}+s\left(\pi^{*}+d \delta\right)+a \alpha+b \beta+h \delta_{\mathrm{H}}+e \xi,
$$

where $\delta_{\mathrm{H}}$ is the Hildebrand's solubility parameter, a measure of the solvent-solvent interactions that are interrupted in creating a cavity for the solute. $\pi^{*}$, an index of solvent dipolarity or polarizability, measures the ability of the solvent to stabilize a charge or a dipole by virtue of its dielectric effect. $\delta$, a polarizability correction term, equals 0.0 for nonchlorinated aliphatic solvents, 0.5 for polychlorinated aliphatics, and 1.0 for aromatic solvents. Solvatochromic parameter $\beta$, representing scale of solvent HBD (hydrogen-bond donor) acidities, describes the ability of solvent to donate a proton in a solvent-to-solute H-bond. $\alpha$, scale of HBA (hydrogenbond acceptor) basicities, provides a measure of the solvent's ability to accept a proton (donate an electron pair) in a soluteto-solvent $\mathrm{H}$-bond. The $\xi$ parameter, a measure of coordinate covalency, equals -0.20 for $\mathrm{P}=\mathrm{O}$ bases, 0.0 for $\mathrm{C}=\mathrm{O}, \mathrm{S}=\mathrm{O}$, and $\mathrm{N}=\mathrm{O}$ bases, 0.20 for single-bonded oxygen bases, 0.60 for pyridine bases, and 1.00 for $s p^{3}$-hybridized amine bases. The coefficients $p, s, e, d, a, h$, and $b$ are the regression coefficients that measure the relative susceptibilities of $X Y Z$ to indicated solvent property scale. Equation (37) is adopted to describe the effect of diluents on the values of distribution coefficients $\left(K_{D}\right)$ :

$$
\log _{10} K_{D}=\log _{10} K_{D}{ }^{0}+s\left(\pi^{*}+d \delta\right)+a \alpha+b \beta+h \delta_{\mathrm{H}}+e \xi,
$$

where the parameters $\pi^{*}, \delta, \beta$, and $\alpha$ refer to the diluents, and $K_{D}{ }^{0}$ represents the distribution coefficient for an ideal diluent. The fifth term of (38), which contains the solubility parameter $\delta_{\mathrm{H}}$, does not affect the values of the objective function $\left(\log _{10} K_{D}\right)$ significantly and the value of $\xi=0$ is considered for the diluents used in this study. Thus, (38) results in

$$
\log _{10} K_{D}=\log _{10} K_{D}{ }^{0}+s\left(\pi^{*}+d \delta\right)+b \beta+a \alpha .
$$

Equation (39) can be adopted to describe the effect of diluents on the values of distribution coefficients $\left(K_{D}\right)$. In case, a mixture of diluents is used with the extractant, the solvatochromic parameters of the solvent mixtures are calculated as [77]

$$
S P_{12}=X_{1} S P_{1}+\left(1-X_{1}\right) S P_{2}
$$

where $X_{1}$ is the mole fraction of the first solvent and $X_{2}=$ $1-X_{1}$ is the mole fraction of the second solvent. $S P_{1}$ is the solvatochromic parameter of the first solvent and $S P_{2}$ is the solvatochromic parameter of the second solvent in solvent mixtures. The solvatochromic parameters of different diluents can be found in the study by Kamlet et al. [74].

2.2. Kinetic Studies on Reactive Extraction of Carboxylic Acids. Kinetic studies are equally essential as equilibrium studies for the complete design of a reactive extraction unit. Lewis type stirred cell [78], cylindrical stirring vessel with highly agitated system [50], stirred cell with a microporous hydrophobic membrane [79], and so forth were used to perform the kinetic studies on the reactive extraction of various carboxylic acids. In these studies, the investigators have described and analyzed the kinetic mechanism of reactive extraction using formal elementary kinetic model, a mechanism of reactions of acid-amine complexes [50], theory of extraction accompanied by a chemical reaction [79], and so forth. The estimation of the intrinsic kinetic parameters such as rate constants (forward and backward) and reaction order were also carried out using experimental data. According to their findings, the reaction between the acid and the extractant not only depends on the composition of the organic and aqueous phases, it also depends on the hydrodynamic parameters (volume ratio of phases, interfacial area and speed of agitation) of the system which also confirmed the region of the (mass transfer controlled or reaction controlled) reaction. In a study by Jun et al. [80] in 2007, it was observed that the reaction rates were affected by $\mathrm{pH}$ and contamination present in the aqueous phase. At a $\mathrm{pH}$ greater than the $\mathrm{p} K_{a}$ of acid, more dissociation took place leading to the reduction in the extraction efficiency. Therefore, it was recommended that, to have an effective separation of acid from the production media, the $\mathrm{pH}$ of the fermentation broth should be kept at a value less than the $\mathrm{p} K_{a}$ of the acid. Further, a brief review of the kinetic studies on reactive extraction is summarized in Table 2 to have an overview of the reactive kinetics of different carboxylic acids.

2.2.1. Kinetic Model. A comprehensive study on the theory of extraction accompanied with chemical reaction in a stirred cell is proposed by Doraiswamy and Sharma [79] in 1984 to determine the effect of chemical reaction on the specific rate of reaction. With the help of the film and renewal theories with physico-chemical and hydrodynamic parameters, they have classified the reactive system into four reaction regimes (very slow, slow, fast, and instantaneous) depending on their relative diffusion and reaction rates (Table 3 ).

The value of physical mass transfer coefficient $\left(k_{L}\right)$ is required to confirm the regime of reaction. This is obtained 


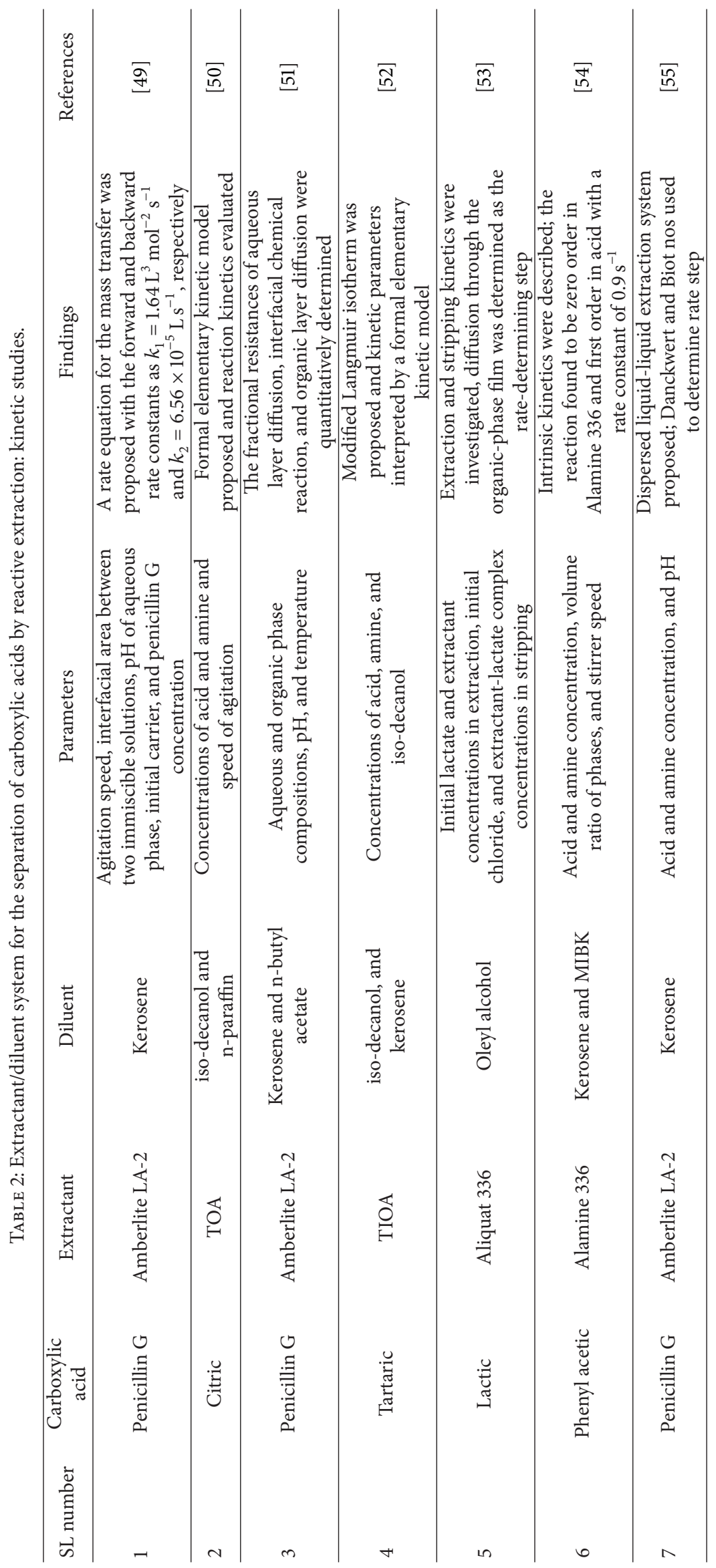


TABLE 3: Classical limiting regimes for irreversible reaction in a stirred cell.

\begin{tabular}{|c|c|c|c|c|c|c|}
\hline \multirow{2}{*}{ Regime } & \multirow{2}{*}{ Description } & \multirow{2}{*}{ Hatta Number (Ha) } & \multicolumn{4}{|c|}{ Effect on the specific rate of extraction $\left(\mathrm{mol} \cdot \mathrm{m}^{-2} \cdot \mathrm{s}^{-1}\right)$} \\
\hline & & & $\begin{array}{l}\overline{[\mathrm{HC}]} \\
\mathrm{mol} \cdot \mathrm{L}^{-1}\end{array}$ & $\begin{array}{c}{[S]} \\
\mathrm{mol} \cdot \mathrm{L}^{-1}\end{array}$ & $\begin{array}{l}\text { Stirrer speed } \\
(N, \mathrm{rpm})\end{array}$ & $\begin{array}{c}\text { Volume ratio of } \\
\text { phases }\end{array}$ \\
\hline 1 & Very slow & \multirow[b]{2}{*}{$<<1$} & $\alpha[\overline{\mathrm{HC}}]^{m}$ & $\alpha[\overline{\mathrm{S}}]^{n}$ & None & $\alpha V_{\text {org }}$ \\
\hline 2 & Slow & & $\alpha[\overline{\mathrm{HC}}]$ & None & $\begin{array}{l}\text { Increases with } \\
\text { increase in the } \\
\text { speed of stirring }\end{array}$ & None \\
\hline 3 & Fast & \multirow[b]{2}{*}{$>>1$} & $\alpha[\overline{\mathrm{HC}}]^{(m+1) / 2}$ & $\alpha[\overline{\mathrm{S}}]^{n / 2}$ & None & None \\
\hline 4 & Instantaneous & & None & $\alpha[S]$ & $\begin{array}{l}\text { Increases with } \\
\text { increase in the } \\
\text { speed of stirring }\end{array}$ & None \\
\hline
\end{tabular}

by conducting physical extraction of acid from aqueous phase with pure diluent. For a batch process a differential mass balance yields the following equation:

$$
V_{\mathrm{aq}} \frac{d C_{\mathrm{org}}}{d t}=k_{L} A_{c}\left(C_{\mathrm{org}}^{*}-C_{\mathrm{org}}\right),
$$

where $A_{c}$ is the interfacial area $\left(\mathrm{m}^{2}\right) ; V_{\mathrm{aq}}$ is the aqueous phase volume $\left(\mathrm{m}^{3}\right) ; C_{\mathrm{org}}^{*}$ is the equilibrium acid concentration in the organic phase. The time-dependent concentration of acid in the organic phase is obtained by integrating (42) as

$$
\ln \left(\frac{C_{\text {org }}^{*}}{C_{\text {org }}^{*}-C_{\text {org }}}\right)=\frac{k_{L} A_{c}}{V_{\text {org }}} t .
$$

A plot of $\ln \left(C_{\text {org }}^{*} /\left(C_{\text {org }}^{*}-C_{\text {org }}\right)\right)$ versus time $(t)$ yields a straight line and the slope is used to evaluate physical mass transfer coefficient $\left(k_{L}\right)$.

The reaction between acid and extractant is reversible. This problem of reversibility can be avoided by measuring the initial specific rate of reaction which is governed only by the forward reaction. Therefore, in this study, the initial specific rate of extraction, $R_{\mathrm{HC}, 0}\left(\mathrm{~mol} \cdot \mathrm{m}^{-2} \cdot \mathrm{s}^{-1}\right)$ is calculated from experimental data using the following equation:

$$
R_{\mathrm{HC}, 0}=\frac{V_{\mathrm{org}}}{A_{c}}\left(\frac{d C_{\mathrm{HC}, \mathrm{org}}}{d t}\right)_{t=0} .
$$

$\left(d C_{\mathrm{HC} \text {,org }} / d t\right)_{t=0}$ is the initial slope of curve which is a representation of the concentration in the organic phase versus time $(t)$. The values of $R_{\mathrm{HC}, 0}$ are determined with various experimental conditions and used to determine the probable effect of the important variables and to draw an inference on the appropriate kinetics of reactive extraction. In this regard, the effects of the speed of agitation $(N)$ and volume ratio of the phases $\left(V_{\text {org }} / V_{\text {aq }}\right)$ on the initial specific rate of extraction must be examined to determine the reaction regime. Therefore, based on the guidelines provided by Doraiswamy and Sharma [79], the reactive extraction of acid with extractant in diluent is governed by the following equation:

$$
R_{\mathrm{HC}, 0}=k_{\alpha^{\prime} \beta^{\prime}}[\overline{\mathrm{HC}}]^{\alpha^{\prime}}[\overline{\mathrm{S}}]^{\beta^{\prime}}
$$

where $\alpha^{\prime}$ and $\beta^{\prime}$ are the orders of the reaction with respect to acid and extractant, respectively, and $k_{\alpha^{\prime} \beta^{\prime}}$ is the rate constant of the reaction.

For a $\left(\alpha^{\prime}, \beta^{\prime}\right)$ reaction taking place in the organic phase with a rate law shown in (44) and with a high excess of extractant, Hatta number $(\mathrm{Ha})$ is given by a general expression as

$$
H a=\frac{\sqrt{\left(2 /\left(\alpha^{\prime}+1\right)\right) k_{\alpha^{\prime} \beta^{\prime}}[\overline{\mathrm{HC}}]^{\alpha^{\prime}-1}[\overline{\mathrm{S}}]^{\beta^{\prime}} D_{\mathrm{HC}}}}{k_{L}} .
$$

$D_{\mathrm{HC}}$ is the diffusion coefficient of acid into diluent. The value of $D_{\mathrm{HC}}$ is estimated using Wilke-Change (1955) and ReddyDoraiswamy (1967) equations which are given by (46) and (47), respectively:

$$
\begin{gathered}
D_{\mathrm{HC}}=7.4 \times 10^{-12} \frac{T \sqrt{\Psi M}}{\eta\left(\forall^{\text {acid }}\right)^{0.6}} \\
D_{\mathrm{HC}}=10^{-11} \frac{T \sqrt{M}}{\eta\left(\forall^{\text {diluent }} \forall^{\text {acid }}\right)^{1 / 3}},
\end{gathered}
$$

where $\Psi$ denotes the diluent association factor; $\forall$ signifies the molar volume of the component; $T$ is temperature (K); $M$ and $\eta$ represent molecular weight $\left(\mathrm{kg} \cdot \mathrm{kmol}^{-1}\right)$ and viscosity $\left(\mathrm{kg} \cdot \mathrm{m}^{-1} \cdot \mathrm{s}^{-1}\right)$ of the diluent, respectively.

To determine the effect of reaction on the pure mass transfer of acid from the aqueous to the organic phase, the enhancement factor for the reactive extraction of acid is calculated using

$$
\Phi=\frac{R_{\mathrm{HC}, 0}}{k_{L} C_{\mathrm{org}}^{*}}
$$

\section{Conflict of Interests}

The authors declare that there is no conflict of interests regarding the publication of this paper.

\section{References}

[1] H. Bart, Reactive Extraction, Springer, Berlin, Germany, 1st edition, 2001. 
[2] R. Marr and H. J. Bart, "Solvent-extraction," Chemie Ingenieur Technik, vol. 54, no. 2, pp. 119-129, 1982.

[3] A. S. Kertes and C. J. King, "Extraction chemistry of fermentation product carboxylic acids," Biotechnology and Bioengineering, vol. 28, no. 2, pp. 269-282, 1986.

[4] C. H. Holten, Lactic Acid: Properties and Chemistry of Lactic Acid and Derivatives, Springer, Berlin, Germany, 1st edition, 1971.

[5] R. Wennersten, "Extraction of carboxylic acid from fermentation broth in using solution of tertiary amine," Journal of Chemical Technology and Biotechnology, no. 2, pp. 85-94, 1983.

[6] J. Hartl and R. Marr, "Extraction processes for bioproduct separation," Separation Science and Technology, vol. 28, no. 1-3, pp. 805-819, 1993.

[7] D. Cascaval and A. I. Galaction, "New separation techniques on bioseparations 1. Reactive extraction," Chemical Industry, vol. 58, no. 9, pp. 375-386, 2004.

[8] K. L. Wasewar, A. B. M. Heesink, G. F. Versteeg, and V. G. Pangarkar, "Reactive extraction of lactic acid using alamine 336 in MIBK: equilibria and kinetics," Journal of Biotechnology, vol. 97, no. 1, pp. 59-68, 2002.

[9] K. L. Wasewar, A. B. M. Heesink, G. F. Versteeg, and V. G. Pangarkar, "Equilibria and kinetics for reactive extraction of lactic acid using Alamine 336 in decanol," Journal of Chemical Technology \& Biotechnology, vol. 77, no. 9, pp. 1068-1075, 2002.

[10] S. Kumar and B. V. Babu, "Process intensification for separation of carboxylic acids from fermentation broths using reactive extraction," Journal of Future Engineering and Technology, vol. 3, pp. 21-28, 2008.

[11] J. M. Wardell and C. J. King, "Solvent equilibria for extraction of carboxylic acids from water," Journal of Chemical \& Engineering Data, vol. 23, no. 2, pp. 144-148, 1978.

[12] V. Bízek, J. Horáček, R. Řeřicha, and M. Koušová, “Amine extraction of hydroxycarboxylic acids. 1. Extraction of citric acid with 1-octanol/n-heptane solutions of trialkylamine," Industrial \& Engineering Chemistry Research, vol. 31, no. 6, pp. 1554-1562, 1992.

[13] J. A. Tamada, A. S. Kertes, and C. J. King, "Extraction of carboxylic acids with amine extractants. 1. Equilibria and law of mass action modeling," Industrial and Engineering Chemistry Research, vol. 29, no. 7, pp. 1319-1326, 1990.

[14] D. H. Han and W. H. Hong, "Reactive extraction of lactic acid with trioctylamine/methylene chloride/n-hexane," Separation Science and Technology, vol. 31, no. 8, pp. 1123-1135, 1996.

[15] E. Kahya, E. Bayraktar, and Ü. Mehmeto, "Optimization of process parameters for reactive lactic acid extraction," Turkish Journal of Chemistry, vol. 25, no. 2, pp. 223-230, 2001.

[16] J. A. Tamada and C. J. King, "Extraction of carboxylic acids with amine extractants. 3. Effect of temperature, water coextraction, and process considerations," Industrial and Engineering Chemistry Research, vol. 29, no. 7, pp. 1333-1338, 1990.

[17] V. M. Yabannavar and D. I. C. Wang, "Strategies for reducing solvent toxicity in extractive fermentations," Biotechnology and Bioengineering, vol. 37, no. 8, pp. 716-722, 1991.

[18] L. J. Poole and C. J. King, "Regeneration of carboxylic acidamine extracts by back-extraction with an aqueous solution of a volatile amine," Industrial \& Engineering Chemistry Research, vol. 30, no. 5, pp. 923-929, 1991.

[19] H. Bart, "From single droplet to column design," in Proceedings of the 6th World Congress of Chemical Engineering, Melbourne, Australia, September 2001.
[20] R. S. Juang and R. H. Huang, "Kinetic studies on lactic acid extraction with amine using a microporous membrane-based stirred cell," Journal of Membrane Science, vol. 129, no. 2, pp. 185196, 1997.

[21] R. S. Juang and R. H. Huang, "Equilibrium studies on reactive extraction of lactic acid with an amine extractant," Chemical Engineering Journal, vol. 65, no. 1, pp. 47-53, 1997.

[22] Y. K. Hong and W. H. Hong, "Reactive extraction of lactic acid with mixed tertiary amine extractants," Biotechnology Techniques, vol. 13, no. 12, pp. 915-918, 1999.

[23] G. Malmary, J. Albet, A. Putranto, H. Hanine, and J. Molinier, "Recovery of aconitic and lactic acids from simulated aqueous effluents of the sugar-cane industry through liquid-liquid extraction," Journal of Chemical Technology and Biotechnology, vol. 75, no. 12, pp. 1169-1173, 2000.

[24] Y. Li, Y. Wang, Y. Li, and Y. Dai, "Extraction of glyoxylic acid, glycolic acid, acrylic acid, and benzoic acid with trialkylphosphine oxide," Journal of Chemical and Engineering Data, vol. 48, no. 3, pp. 621-624, 2003.

[25] H. Uslu and I. Inci, "(Liquid + liquid) equilibria of the (water + propionic acid + Aliquat $336+$ organic solvents) at $\mathrm{T}=298.15$ K,' Journal of Chemical Thermodynamics, vol. 39, no. 5, pp. 804809, 2007.

[26] A. Keshav, K. L. Wasewar, and S. Chand, "Extraction of propionic acid using different extractants (tri-n-butylphosphate, tri-n-octylamine, and Aliquat 336)," Industrial and Engineering Chemistry Research, vol. 47, no. 16, pp. 6192-6196, 2008.

[27] G. Kyuchoukov, A. F. Morales, J. Albet, G. Malmary, and J. Molinier, "On the possibility of predicting the extraction of dicarboxylic acids with tributylphosphate dissolved in a diluent," Journal of Chemical \& Engineering Data, vol. 53, no. 3, pp. 639-647, 2008.

[28] S. Kumar, K. L. Wasewar, and B. V. Babu, "Intensification of nicotinic acid separation using organophosphorous solvating extractants by reactive extraction," Chemical Engineering and Technology, vol. 31, no. 11, pp. 1584-1590, 2008.

[29] H. Uslu, Ş. I. Kirbaşlar, and K. L. Wasewar, "Reactive extraction of levulinic acid by amberlite LA-2 extractant," Journal of Chemical and Engineering Data, vol. 54, no. 3, pp. 712-718, 2009.

[30] H. Uslu, C. Bayat, S. Gökmen, and Y. Yorulmaz, "Reactive extraction of formic acid by amberlite LA-2 extractant," Journal of Chemical and Engineering Data, vol. 54, no. 1, pp. 48-53, 2009.

[31] S. Kumar and B. V. Babu, "Extraction of pyridine-3-carboxylic acid using 1-dioctylphosphoryloctane (TOPO) with different diluents: equilibrium studies," Journal of Chemical and Engineering Data, vol. 54, no. 9, pp. 2669-2677, 2009.

[32] Y. S. Asci and I. Inci, "Extraction of glycolic acid from aqueous solutions by amberlite la-2 in different diluent solvents," Journal of Chemical and Engineering Data, vol. 54, no. 10, pp. 2791-2794, 2009.

[33] Ş. S. Bayazit, H. Uslu, and I. Inci, "Comparative equilibrium studies for citric acid by amberlite LA-2 or Tridodecylamine (TDA)," Journal of Chemical \& Engineering Data, vol. 54, no. 7, pp. 1991-1996, 2009.

[34] N. Pehlivanoğlu, H. Uslu, and Ş. I. Kirbaşlar, "Experimental and modeling studies on the extraction of glutaric acid by trioctylamine," Journal of Chemical and Engineering Data, vol. 54, no. 12, pp. 3202-3207, 2009.

[35] A. Labbaci, G. Kyuchoukov, J. Albet, and J. Molinier, "Detailed investigation of lactic acid extraction with tributylphosphate dissolved in dodecane," Journal of Chemical and Engineering Data, vol. 55, no. 1, pp. 228-233, 2010. 
[36] Y. S. Asci and I. Inci, "Extraction equilibria of acrylic acid from aqueous solutions by amberlite LA-2 in various diluents," Journal of Chemical and Engineering Data, vol. 55, no. 7, pp. 2385-2389, 2010.

[37] S. Şahin, Ş. S. Bayazit, M. Bilgin, and I. Inci, "Investigation of formic acid separation from aqueous solution by reactive extraction: effects of extractant and diluent," Journal of Chemical \& Engineering Data, vol. 55, no. 4, pp. 1519-1522, 2010.

[38] Z. Ren, W. Zhang, J. Li, S. Wang, J. Liu, and Y. Lv, "Effect of organic solutions on the stability and extraction equilibrium of penicillin G," Journal of Chemical and Engineering Data, vol. 55, no. 8, pp. 2687-2694, 2010.

[39] Y. S. Asci, İ. İnci, and H. Uslu, "LSER modelim extraction of succinic acid by tridodecyl amine dissolved in 2-octanone and 1-octanlol," Journal of Industrial and Engineering Chemistry, vol. 32, pp. 1951-1957, 2010.

[40] K. L. Wasewar, D. Shende, and A. Keshav, "Reactive extraction of itaconic acid using tri-n-butyl phosphate and aliquat 336 in sunflower oil as a non-toxic diluent," Journal of Chemical Technology and Biotechnology, vol. 86, no. 2, pp. 319-323, 2011.

[41] S. Kumar, D. Datta, and B. V. Babu, "Differential evolution approach for reactive extraction of propionic acid using tri- $n$ butyl phosphate (TBP) in kerosene and 1-decanol," Materials and Manufacturing Processes, vol. 26, no. 9, pp. 1222-1228, 2011.

[42] I. Inci, Y. S. Asci, and A. F. Tuyun, "Reactive extraction of L (+) tartaric acid by amberlite LA-2 in different solvents," E-Journal of Chemistry, vol. 8, supplement 1, pp. S509-S515, 2011.

[43] K. L. Wasewar and D. Shende, "Equilibrium study for reactive extraction of caproic acid in MIBK and Xylene," Engineering, vol. 3, pp. 829-835, 2011.

[44] D. Caşcaval, L. Kloetzer, and A.-I. Galaction, "Influence of organic phase polarity on interfacial mechanism and efficiency of reactive extraction of acetic acid with tri-n-octylamine," Journal of Chemical \& Engineering Data, vol. 56, no. 5, pp. 25212526, 2011.

[45] M. D. Waghmare, K. L. Wasewar, S. S. Sonawane, and D. Z. Shende, "Natural nontoxic solvents for recovery of picolinic acid by reactive extraction," Industrial \& Engineering Chemistry Research, vol. 50, no. 23, pp. 13526-13537, 2011.

[46] L. Zhang, F. Yu, Z. Chang, Y. Guo, and D. Li, "Extraction equilibria of picolinic acid with rrialkylamine/n-octanol," Journal of Chemical and Engineering Data, vol. 57, no. 2, pp. 577-581, 2012.

[47] Y.-P. Ren, J.-J. Wang, X.-F. Li, and X.-H. Wang, "Reactive extraction of short-chain fatty acids from synthetic acidic fermentation broth of organic solid wastes and their stripping," Journal of Chemical \& Engineering Data, vol. 57, no. 1, pp. 46-51, 2012.

[48] A. Keshav, P. Norge, and K. L. Wasewar, "Reactive extraction of citric acid using tri-n-octylamine in nontoxic natural diluents: part 1-equilibrium studies from aqueous solutions," Applied Biochemistry and Biotechnology, vol. 167, no. 2, pp. 197-213, 2012.

[49] S. S. Wang and C. J. Lee, "Kinetics of penicillin G extraction by Amberlite LA-2 as a mobile carrier in a constant-interfacearea cell," Chemical Engineering Journal and the Biochemical Engineering Journal, vol. 58, no. 3, pp. 285-290, 1995.

[50] F. A. Poposka, K. Nikolovski, and R. Tomovska, "Kinetics, mechanism and mathematical modelling of extraction of citric acid with isodecanol/ $n$-paraffins solutions of trioctylamine," Chemical Engineering Science, vol. 53, no. 18, pp. 3227-3237, 1998.

[51] R.-S. Juang and Y.-S. Lin, "Investigation on interfacial reaction kinetics of Penicillin G and Amberlite LA-2 from membrane flux measurements," Journal of Membrane Science, vol. 141, no. 1, pp. 19-30, 1998.

[52] F. A. Poposka, J. Prochazka, R. Tomovska, and A. Grizo, "Extraction of tartaric acid from aqueous solutions with triiso-octylamine (HOSTAREX A 324). Equilibrium and kinetics," Chemical Engineering Science, vol. 55, no. 9, pp. 1591-1604, 2000.

[53] M. Hironaka, M. Hirata, H. Takanashi, T. Hano, and S. Miura, "Kinetics of lactic acid extraction with quaternary ammonium salt," Separation Science and Technology, vol. 36, no. 13, pp. 29272943, 2001.

[54] H. K. Gaidhani, K. L. Wasewar, and V. G. Pangarkar, "Intensification of enzymatic hydrolysis of penicillin G: Part 1. Equilibria and kinetics of extraction of phenyl acetic acid by Alamine 336," Chemical Engineering Science, vol. 57, no. 11, pp. 1979-1984, 2002.

[55] S. C. Lee, "Kinetics of reactive extraction of Penicillin G by Amberlite LA-2 in kerosene," AIChE Journal, vol. 50, no. 1, pp. 119-126, 2004.

[56] J. A. Tamada and C. J. King, "Extraction of carboxylic acids with amine extractants. 2. Chemical interactions and interpretation of data," Industrial and Engineering Chemistry Research, vol. 29, no. 7, pp. 1327-1333, 1990.

[57] Y. Tong, M. Hirata, H. Takanashi, T. Hano, M. Matsumoto, and S. Miura, "Solvent screening for production of lactic acid by extractive fermentation," Separation Science and Technology, vol. 33, no. 10, pp. 1439-1453, 1998.

[58] A. Keshav, S. Chand, and K. L. Wasewar, "Equilibrium studies for extraction of propionic acid using tri- $n$-butyl phosphate in different solvents," Journal of Chemical \& Engineering Data, vol. 53, no. 7, pp. 1424-1430, 2008.

[59] S. Kumar and B. V. Babu, "Process intensification of nicotinic acid production via enzymatic conversion using reactive extraction," Chemical and Biochemical Engineering Quarterly, vol. 23, no. 3, pp. 367-376, 2009.

[60] Z. Gu, B. Glatz, and C. E. Glatz, "Propionic acid production by extractive fermentation. I. Solvent considerations," Biotechnology and Bioengineering, vol. 57, pp. 454-461, 1998.

[61] C. Q. Ma, J. C. Li, J. H. Qiu, M. Wang, and P. Xu, "Recovery of pyruvic acid from biotransformation solutions," Applied Microbiology and Biotechnology, vol. 70, no. 3, pp. 308-314, 2006.

[62] T. Kirsch and G. Maurer, "Distribution of binary mixtures of citric, acetic and oxalic acid between water and organic solutions of tri-n-octylamine Part I. Organic solvent toluene," Fluid Phase Equilibria, vol. 131, no. 1-2, pp. 213-231, 1997.

[63] R. Canari and A. M. Eyal, "Selectivity in monocarboxylic acids extraction from their mixture solutions using an amine-based extractant: effect of $\mathrm{pH}$,' Industrial and Engineering Chemistry Research, vol. 42, no. 7, pp. 1301-1307, 2003.

[64] M. Siebold, P. van Frieling, R. Joppien, D. Rindfleisch, K. Schugerl, and H. Roper, "Comparison of the production of lactic acid by three different lactobacilli and its recovery by extraction and electrodialysis," Process Biochemistry, vol. 30, no. 1, pp. 8195, 1995.

[65] T. A. Barbari and C. J. King, "Equilibrium distribution coefficients for extraction of chlorinated hydrocarbons and aromatics from water into undecane," Environmental Science and Technology, vol. 16, no. 9, pp. 624-627, 1982.

[66] C. L. Munson and C. J. King, "Factors influencing solvent selection for extraction of ethanol from aqueous solutions," Industrial \& Engineering Chemistry Process Design and Development, vol. 23, no. 1, pp. 109-115, 1984. 
[67] P. D. Mackenzie and C. J. King, "Combined solvent extraction and stripping for removal and isolation of ammonia from sour waters," Industrial and Engineering Chemistry Process Design and Development, vol. 24, no. 4, pp. 1192-1200, 1985.

[68] S. T. Yang, S. A. White, and S. T. Hsu, "Extraction of carboxylic acids with tertiary and quaternary amines: effect of $\mathrm{pH}$," Industrial \& Engineering Chemistry Research, vol. 30, no. 6, pp. 1335-1342, 1991.

[69] J. Procházka, A. Heyberger, V. Bízek, M. Koušová, and E. Volaufová, "Amine extraction of hydroxycarboxylic acids. 2. Comparison of equilibria for lactic, malic, and citric acids," Industrial and Engineering Chemistry Research, vol. 33, no. 6, pp. 1565-1573, 1994.

[70] R.-S. Juang, R.-H. Huang, and R.-T. Wu, "Separation of citric and lactic acids in aqueous solutions by solvent extraction and liquid membrane processes," Journal of Membrane Science, vol. 136, no. 1-2, pp. 89-99, 1997.

[71] F. A. Poposka, K. Nikolovski, and R. Tomovska, "Equilibria and mathematical models of extraction of citric acid with isodecanol/n-paraffins solutions of trioctylamine," Journal of Chemical Engineering of Japan, vol. 30, no. 5, pp. 777-785, 1997.

[72] M. Matsumoto, T. Otono, and K. Kondo, "Synergistic extraction of organic acids with tri- $n$-octylamine and tri-n-butylphosphate," Separation and Purification Technology, vol. 24, no. 1-2, pp. 337-342, 2001.

[73] D. Yankov, J. Molinier, J. Albet, G. Malmary, and G. Kyuchoukov, "Lactic acid extraction from aqueous solutions with tri-n-octylamine dissolved in decanol and dodecane," Biochemical Engineering Journal, vol. 21, no. 1, pp. 63-71, 2004.

[74] M. J. Kamlet, J. L. M. Abboud, M. H. Abraham, and R. W. Taft, "Linear solvation energy relationships. 23. A comprehensive collection of the solvatochromic parameters, $\pi^{*}, \beta$ and $\alpha$, and some methods for simplifying the generalized solvatochromic equation," Journal of Organic Chemistry, vol. 48, no. 17, pp. 28772887, 1983.

[75] M. H. Abraham, "Scales of solute hydrogen-bonding: their construction and application to physicochemical and biochemical processes," Chemical Society Reviews, vol. 22, no. 2, pp. 73-83, 1993.

[76] M. H. Abraham, J. M. R. Gola, J. E. Cometto-Muniz, and W. S. Cain, "The solvation properties of nitric oxide," Journal of the Chemical Society, Perkin Transactions 2, no. 10, pp. 2067-2070, 2000.

[77] V. Bízek, J. Horáček, and M. Koušová, "Amine extraction of citric acid: effect of diluent," Chemical Engineering Science, vol. 48, no. 8, pp. 1447-1457, 1993.

[78] Y.-S. Jun, Y. S. Huh, H. H. Won, and Y. K. Hong, "Kinetics of the extraction of succinic acid with tri- $n$-octylamine in 1-octanol solution," Biotechnology Progress, vol. 21, no. 6, pp. 1673-1679, 2005.

[79] L. K. Doraiswamy and M. M. Sharma, Heterogeneous Reactions: Analysis, Examples, and Reactor Design, John Wiley \& Sons, New York, NY, USA, 1st edition, 1984.

[80] Y.-S. Jun, E. Z. Lee, Y. S. Huh, Y. K. Hong, W. H. Hong, and S. Y. Lee, "Kinetic study for the extraction of succinic acid with TOA in fermentation broth; effects of $\mathrm{pH}$, salt and contaminated acid," Biochemical Engineering Journal, vol. 36, no. 1, pp. 8-13, 2007. 

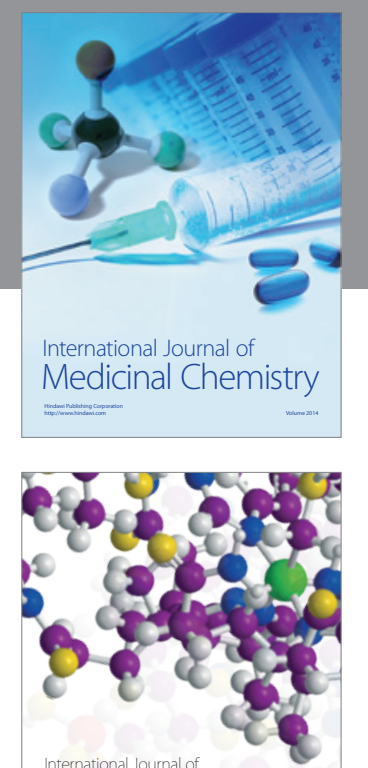

\section{Carbohydrate} Chemistry

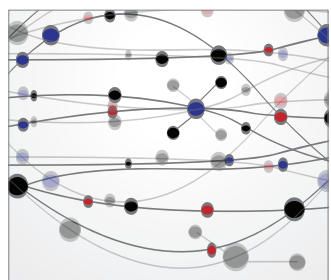

The Scientific World Journal
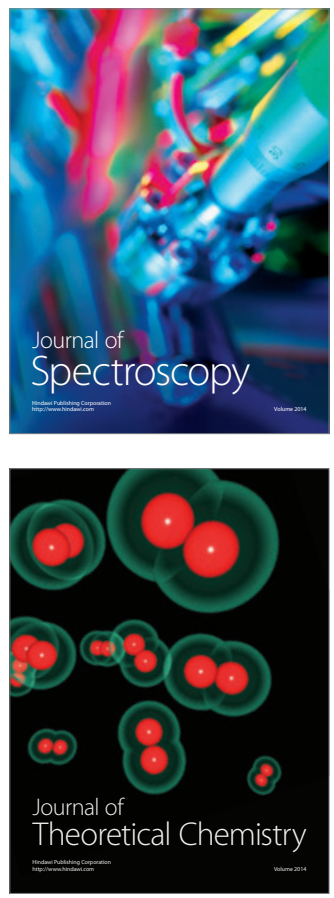
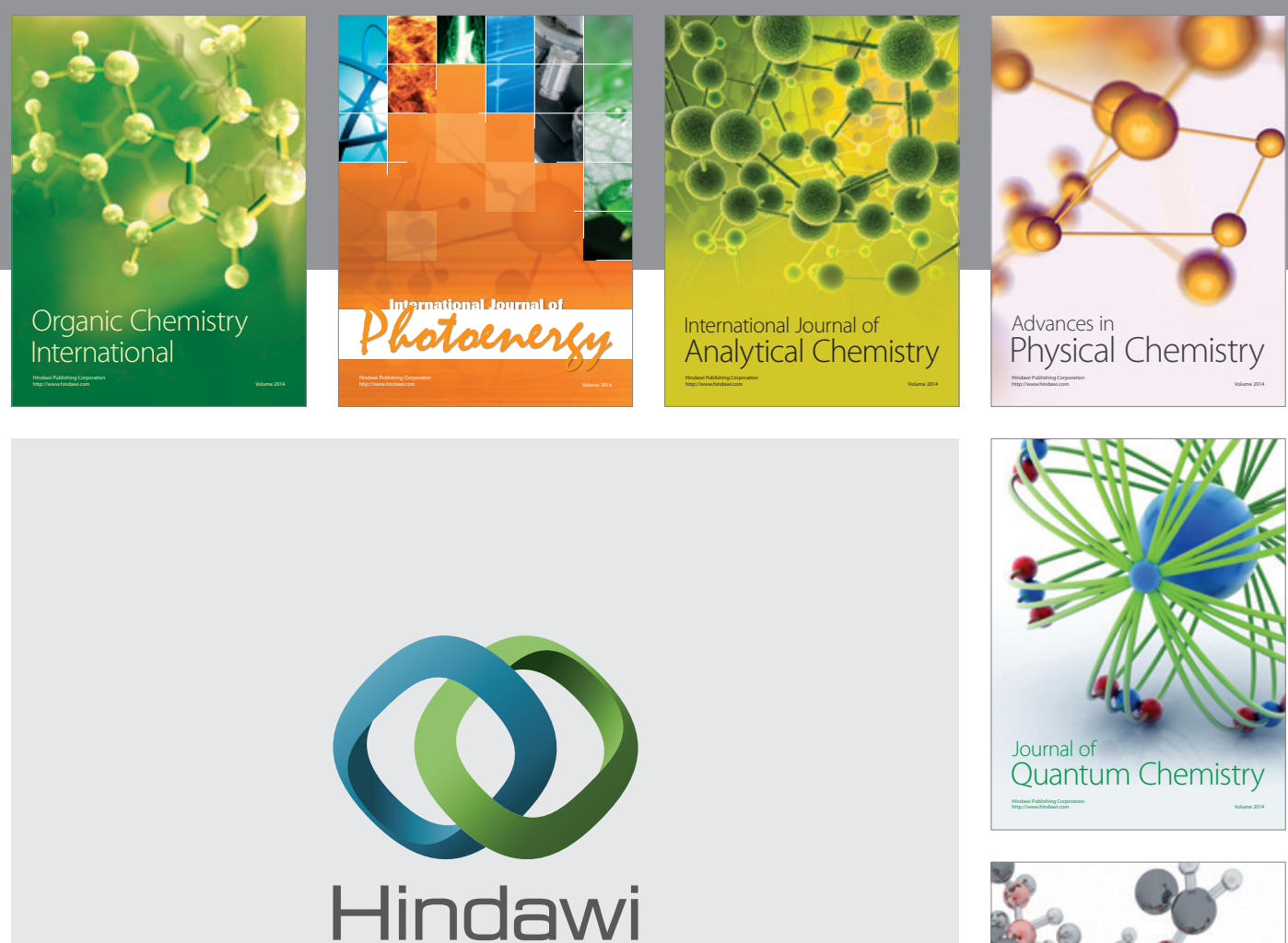

Submit your manuscripts at

http://www.hindawi.com

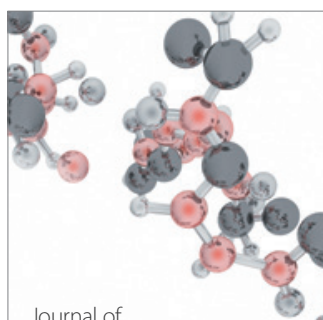

Analytical Methods

in Chemistry

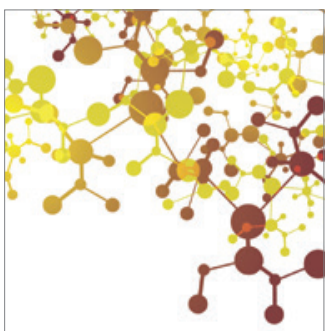

Journal of

Applied Chemistry

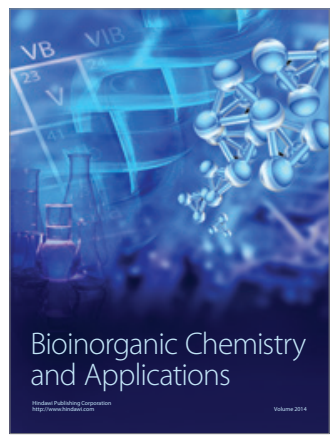

Inorganic Chemistry
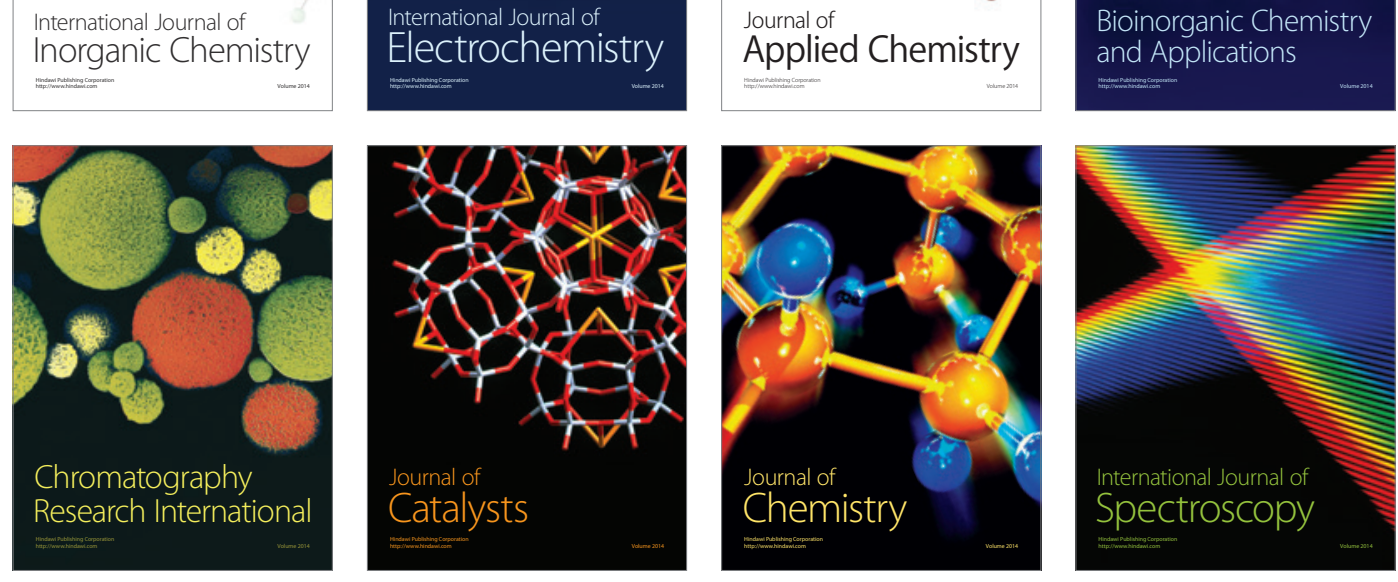